\title{
Impact of supercharging and compression ratio on performance characteristics in a single cylinder DICI engine
}

\author{
Ganesh S. Warkhade*, Alur V. Babu \\ Department of Mechanical Engineering, National Institute of Technology, Warangal 506004, Telangana, India
}

Corresponding Author Email: ganeshwarkhade@gmail.com

https://doi.org/10.18280/ijht.360323

Received: 31 Janauary 2018

Accepted: 7 September 2018

\section{Keywords:}

compression ignition engine, biodiesel, combustion, linum usitatissimum, performance, supercharging

\begin{abstract}
This work investigated the influence of variation of supercharging pressure and compression ratio on performance characteristics in a single cylinder direct injection compression ignition (DICI) engine. The engine was coupled with centrifugal blower type supercharger and compression ratio varied as 14:1, 16:1, 17.5:1 and 18:1. The boost pressures (BPs) were changed at four levels $0.5 \mathrm{kPa}(\mathrm{g}), 1 \mathrm{kPa}(\mathrm{g})$, and $1.5 \mathrm{kPa}(\mathrm{g})$ along with natural aspiration. The experiments were conducted by varying of these two parameters for investigating the impact on performance characteristics using the standard petrodiesel (type 2) as fuel. The obtained results are compared with the standard operating condition of the engine, i.e., natural aspiration at compression ratio 17.5:1. The results show that the improvement in BSFC, BTE was higher at low load, higher compression ratio and at elevated BPs, whereas enhancement for EGT is found to be more at the higher side of working input parameters. The maximum improvement in performance parameters such as BTE, BSFC and EGT, were noted $25.4 \%, 21.7 \%$, and 3.3 $\%$ respectively. The specific power of engine has distinctly increased by $15 \%, 25 \%, 27 \%$, and $16 \%$ at $\mathrm{CR} 14,16,17.5$, and 18 , respectively at $1.5 \mathrm{kPa}(\mathrm{g})$ as compared to standard operating condition.
\end{abstract}

\section{INTRODUCTION}

Gradually declining sources of fuel and high amount of pollutants emitted from the engines are the matter of concern for all the engine developers. Furthermore, the competitive scenario of automotive sector has forced them to adopt the new and innovative technology to increase the performance of the engine and to meet these concerns along with the upcoming stricter pollution norms [1-2]. The pollution level can be reduced up to some extent by using the vegetable oil based biodiesel [3-4]. In line with these objectives of the engine, the engine downsizing by supercharging and turbocharging is one of the age-old technology for getting the improved performance from the same size of the engine or same performance with the reduced size of the engine. These commonly used methods of supercharging [5-8] and turbocharging improves the combustion of fuel in the engine and emission characteristics. The downsizing of internal combustion engine stands for improvement in torque and power, with reduced or same swept volume with the reduction of emission of $\mathrm{CO}_{2}$, fuel consumption, and manufacturing cost of the engine. The smaller engine's lower friction increases its mechanical efficiency and thus effective efficiency. Also, the engine's weight is lowered and improvement in the power to weight ratio. Therefore, downsizing has become an essential feature of the design, in the development of vehicle engines. In the effort of downsizing by turbocharging the small engine is challenging task due to low volume and pulsating nature of exhaust flow rate. This issue was overcome by using a mechanical supercharger but consumes some additional amount of fuel and power to run.
However, recently the engi3ne manufacturers have claimed that over the downsizing of the engine, instead of improving, it deteriorates the emission characteristics [9-10].

The researchers have studied the influence of both supercharging as well as the variable compression ratio separately on performance characteristics of a diesel engine. The supercharging and charge cooling have improved the peak pressure, charging ratio, and brake mean effective pressure by $18 \%, 5 \%$, and $53 \%$ respectively [11]. It is reported that for all tested fuels, the emission of CO and smoke has scaled down considerably and brake thermal efficiency improved notably [12]. The effect of supercharging $(0.2,0.3,0.4 \mathrm{bar}(\mathrm{g}))$ pressure studied on the performance of a direct injection diesel engine using untreated cottonseed oil as fuel under different injection pressures (IPs) 180, 210 and 240 bar. Authors reported that no effect of IP on engine performance but the supercharging improves the performance [13]. Jagadish D. et al. [14] studied the effect of supercharging $(50 \mathrm{kPa})$ using ethanol-diesel blends with palm stearin methyl ester as an additive and noted the enhancement in brake specific fuel consumption, thermal efficiency, exhaust gas temperature, unburned hydrocarbons, carbon monoxide, nitrogen oxide emissions, and smoke opacity. The few recent pieces of literature based on mechanical superchargers for the small engine ( 1 cylinder) are presented in Table 1. The conventional diesel engine works on fixed compression ratio and at full load has a higher combustion pressure problem. This problem could be minimized by reducing the compression ratio. It should also be sufficiently high pressure at starting and at part load operation for better combustion, excellent reliability and longer engine life, low emission. 
Hence, there must be a practical way to vary the compression ratio continuously during the engine operation for meeting the actual load and speed requirement. The engine operates on variable compression ratio (CR) improve the engine performance, efficiency, and exhaust emissions. The engine efficiency and work output are dependent upon the compression ratio. However, the change of compression ratio not yet been designed successfully during running condition due to manufacturing difficulties and balance related issues. Due to increase in compression ratio the loading on engine components, friction, and mechanical losses occurs. However, with changing in compression ratio, the flexibility of using the different types of fuel, better control over peak cylinder pressure, cold start, multi-fuel ability and low load operation, fuel economy, as well as lower engine emissions, obtains. Also with increasing of CR, the fuel consumption decreases. Hence, the variable compression ratio engine useful for facing the twin problems of automobile transportation related to emission and fuel crisis. Hence, in overall using the variable compression ratio is more beneficial in spite of having some losses due to changing the angle for changing the compression ratio [16]. Indicated and thermal efficiency increases with compression ratio while mechanical efficiency decreases [17]. With increasing $\mathrm{CR}$, the fuel consumption decreases. Hence, the variable compression ratio engine useful for facing the twin problems of automobile transportation related to emission (mainly the NOx) and fuel crisis.

Table 1. Literature on small engines with mechanical superchargers

\begin{tabular}{cccc}
\hline Ref. & Supercha-rger & BP & Type of engine \\
\hline$[10]$ & Roots blower-type super-charger & $100,120,140 \mathrm{kPa}(\mathrm{abs})$ & 1 cylinder, CR: 18, 5.1 kW /2400rpm, IP:21.7 MPa \\
{$[11]$} & Two stage reciprocating air compressor & $20,30,40 \mathrm{kPa}(\mathrm{g}))$ & 1 cylinder, 3.7 kW at 1500 rpm, CR: 16.5 \\
{$[12]$} & two-stage reciprocating compressor & $50 \mathrm{kPa}(\mathrm{g})$ & 1 cylinder, 3.7 kW at 1500 rpm, CR: 16.5, IP: 18, 21, and 24 MPa \\
{$[13]$} & two-stage reciprocating compressor & $2,2.5,3 \mathrm{bar}(\mathrm{abs})$ & 1 cylinder, 6 HP at 660 rpm, CR: 16.1, \\
\hline
\end{tabular}

From the above literature, it is noted that both technologies are beneficial for improving the performance characteristics of the engine. However, it is also reported that over limit of these parameters (downsizing and CR) downgrades the performance and emissions of the engine. To the best of author's knowledge, there is no any trace of literature which shows the simultaneous study of both the parameters and economy of using the supercharger for downsizing. Hence, the objective of present study is to investigate the collective effect of varying BPs and CRs on performance characteristics of the engine.

\section{TESTING SETUP AND METHODOLOGY}

The experimental investigation was done using the petrodiesel (PD) fuel type 2. The properties of petrodiesel fuel are given in Table 2. A variable compression ratio single cylinder naturally aspirated (NA) diesel engine is partially modified to supercharge as shown in Figure 1.

A variable speed centrifugal blower $(680 \mathrm{~W})$ type supercharger used for the boosting of the engine. The supercharger connected at the inlet of the air box, which is used as surge tanks at the time of boosting the engine. Tilting engine block principle is applied for changing the compression ratio as shown in the Figure 2.

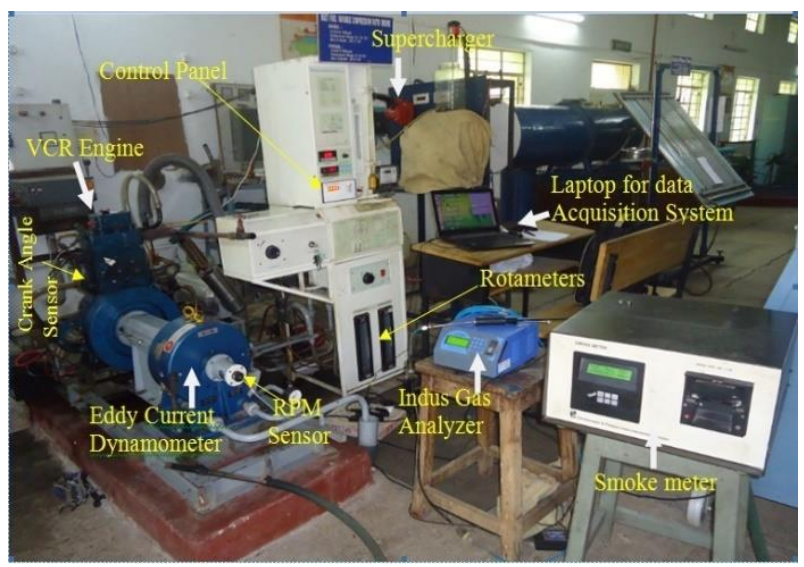

Figure 1. Photographic view of experimental setup
Table 2. Fuel properties

\begin{tabular}{cc}
\hline Properties & PD \\
\hline Density at $40{ }^{0} \mathrm{C}\left(\mathrm{kg} / \mathrm{m}^{3}\right)$ & 829 \\
\hline $\begin{array}{c}\text { Kinematic viscosity at } 40{ }^{0} \mathrm{C} \\
\text { (centistokes) }\end{array}$ & 2.68 \\
\hline Flash point $\left({ }^{0} \mathrm{C}\right)$ & 50 \\
\hline Fire point $\left({ }^{\circ} \mathrm{C}\right)$ & -- \\
\hline Lower Calorific value $(\mathrm{MJ} / \mathrm{kg})$ & 43.5 \\
\hline Lower Calorific value $(\mathrm{MJ} / \mathrm{kg})$ & 43.5 \\
\hline
\end{tabular}

The engine has $3.5 \mathrm{~kW}$ power rating at $1500 \mathrm{rpm}$, bore diameter of $87.5 \mathrm{~mm}$ and stroke length of $110 \mathrm{~mm}$. The capacity of the engine is 0.661 liters with connecting rod length of $234 \mathrm{~mm}$. Mercury manometer 1 (MM1) used for calculating the inlet air flow rate and MM2 for noting the air pressure $(\mathrm{g})$ at the inlet of engine. The experimental setup has been provided with suitable instruments for cylinder pressure, fuel line pressure, and crank angle measurements These measured data are interfaced with a computer for generating the pressure crank angle diagrams. The panel box of the engine set up consisting of digital temperature indicators, digital voltage indicator, and digital load indicator with load control knob of eddy current dynamometer, air-box with orifice meter for measurement of air flow and graduated glass burette for fuel flow indicator. All these experimental data signals are transmitted to Labview based data acquisition software "ICEnginesoft" for online performance/combustion evaluation. For loading the engine the strain gauge type load sensor of range $0-50 \mathrm{~kg}$ used.

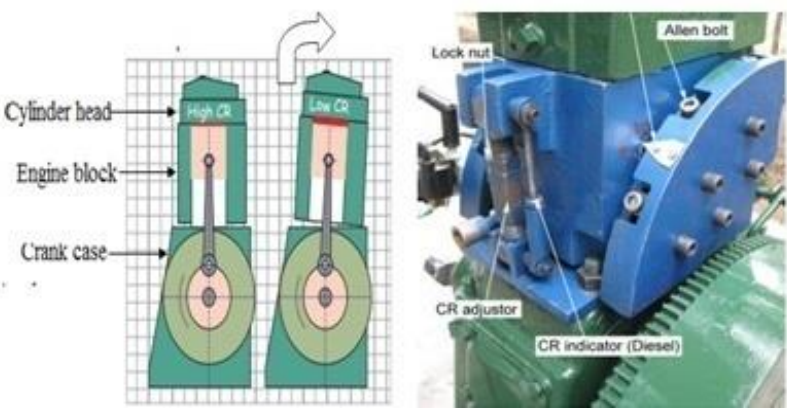

Figure 2. Change of compression ratio 
The temperature sensors RTD, PT100, and K type thermocouples are used to measure exhaust gas and engine cooling water temperature at various locations with accuracies of $\pm 0.1^{\circ} \mathrm{C}$. Cooling water flow rate for engine and eddy current dynamometer was adjusted by using the suitable Rotameter to maintain the engine cooling water temperature around $60{ }^{0} \mathrm{C}$ at outlet. The combustion pressure and fuel line pressure are measured by using the two piezoelectric sensors of range 0 5000 PSI; crank angle sensor is used for measuring the crank angle with a resolution of 1 degree of crank angle.

Many working parameters improve due to the supercharging of the engine. It covers all possible losses and improvement causes due to the supercharging and gives a ratio of concerning effective brake work to the heat added by fuel equivalent mechanical work. Hence the effective thermal efficiency neff of the engine is represented as in equation 1.

$$
\eta_{\text {eff }}=\eta_{c} \eta_{t h} \eta_{c y c} \eta_{m}
$$

where $\eta_{\mathrm{c}}$ indicates fuel combustion efficiency, i.e., the fraction of added fuel burns to add the heat energy and $\eta_{\text {th }}$ process efficiency gives the amount of added heat converted into theoretical work. The cycle efficiency $\eta_{\text {cyc }}$ considers the losses due to the gas exchange processes at high BP account the relative closeness of real cycle process efficiency to theoretical efficiency. The $\eta_{m}$ is the mechanical efficiency of the engine. The economy of using supercharger (or downsizing of the engine) is justified by calculating the specific weight, specific volume, and specific power as given in the equations $2,3,4$.

$$
\begin{aligned}
& \text { Specific_weight }=\frac{\text { Engine _weight }}{\text { Engine }_{-} \text {power }}=\frac{W}{b p} \\
& \text { Specific_volume }=\frac{\text { Engine_volume }}{\text { Engine_power }}=\frac{V_{d}}{b p}
\end{aligned}
$$

Specific_power $=\frac{\text { Engine_power }_{\text {Piston_face_area }}}{\text { Pist }_{\text {f }}}=\frac{b p}{A_{p}}$

Initially, all the measurement equipments were calibrated for accuracy and reliability of recorded data. In the present work, two lower compression ratios (CR) 14:1, 16:1 and one higher CR 18:1 along with the standard CR 17.5:1 selected for the experimental investigations. The experimentation performed at rated CR 17.5:1 and further, testing performed at remaining three CRs, i.e., 14:1, 16:1 and 18:1 and compared the results with rated $\mathrm{CR}$. The injection pressure and timing were kept constant at 210 bar and $23^{\circ}$ bTDC for all observations. Rigorous experimental work was carried out. In each test, before taking the observations, the engine ran for 5 minutes for proper warm-up and stabilizing the set of all working parameters. For reliability and accuracy, a set of observations for output parameters were taken six times for ten cycles each, and the best (less variability) result is considered for analysis purpose.

\section{RESULTS AND DISCUSSIONS}

The present work is carried out to investigate the performance characteristics of a supercharged single cylinder compression ignition engine. These output characteristics are recorded at all CRs and the results of three CRs 14:1, 16:1, 18:1 are compared with rated CR 17.5:1.

\subsection{Power consumption by the supercharger}

The power consumption by the supercharger was measured using the single phase digital energy meter. The energy consumption almost increases linearly with the BPs irrespective of compression ratio used for experimentation in DICI engine.

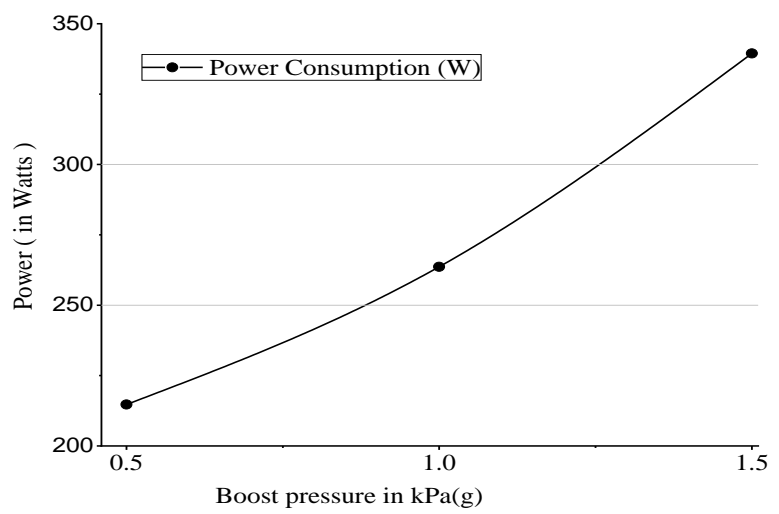

Figure 3. Power consumption by supercharger

As the CR decreases, the volumetric efficiency of compression ignition engine increases with the boosting pressure. At lower CR clearance volume is more to push the more dense air in the cylinder as compared to higher CR. In spite of this, at high BP, supercharger has to run relatively at higher rpm, and hence it consumes more power. Therefore, for power consumption, $\mathrm{BP}$ is more dominant than CR. It consumes $6 \%, 7.5 \%$, and $9.7 \%$ of power at the $0.5,1$, and $1.5 \mathrm{kPa}(\mathrm{g})$ respectively.

\subsection{Brake specific fuel consumption}

Figure 4 depicts the brake specific fuel consumption (BSFC) for the engine operated at rated compression ratio (CR) 17.5 and at different loading conditions varying from $20 \%$ to $100 \%$ for all boosting pressures i.e. NA, $0.5 \mathrm{kPa}(\mathrm{g}), 1$ $\mathrm{kPa}(\mathrm{g}), 1.5 \mathrm{kPa}(\mathrm{g})$. It is observed that at NA, BSFC decreases with rising in load due to improvement in-cylinder pressure and temperature. With rise in BPs, the BSFC decreases, the improvement is more at low load, and it decreases with load and maximum percentage improvement observed was 60.87 $\%$ for BP $1.5 \mathrm{kPa}(\mathrm{g})$ at $20 \%$ load.

Due to the rise in boosting pressure the noted improvement in combustion efficiency of fuel results in increase in mech anical efficiency, effective torque, and brake power. Also due to the increased volumetric efficiency, density, and turbulence of inlet air improve the lean combustion as shown in the figure. At high load, the effect of supercharging is less as compared to low and medium load.

The percentage improvements (reduction) of BSFC for boosting pressures over NA at CR 17.5 are presented in Figure 5. The percentage improvement increases with the boosting pressure, and it is higher at low and partial loads.

At low and partial loads, BP increases the temperature and density of air, high temperature may slightly affect the density, but overall enhances combustion of fuel. This increased 
combustion efficiency of fuel needs the lesser quantity fuel for developing the required power at the particular load.

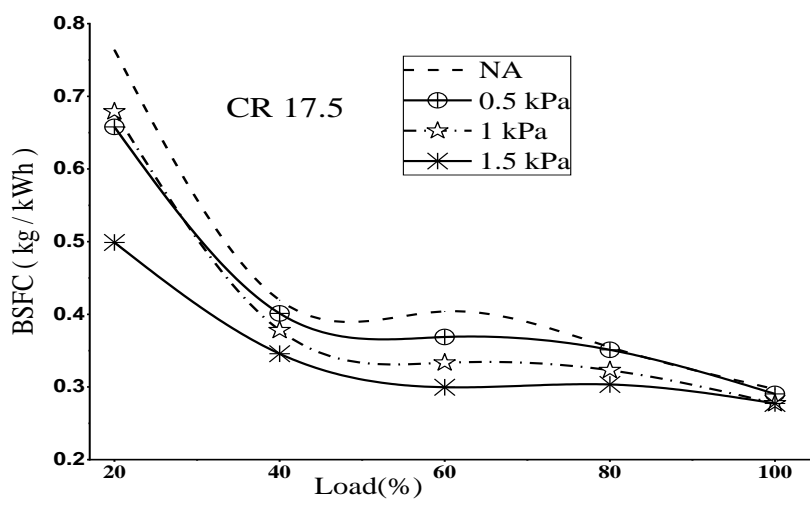

Figure 4. Variation of brake specific fuel consumption at $\mathrm{CR}$ 17.5

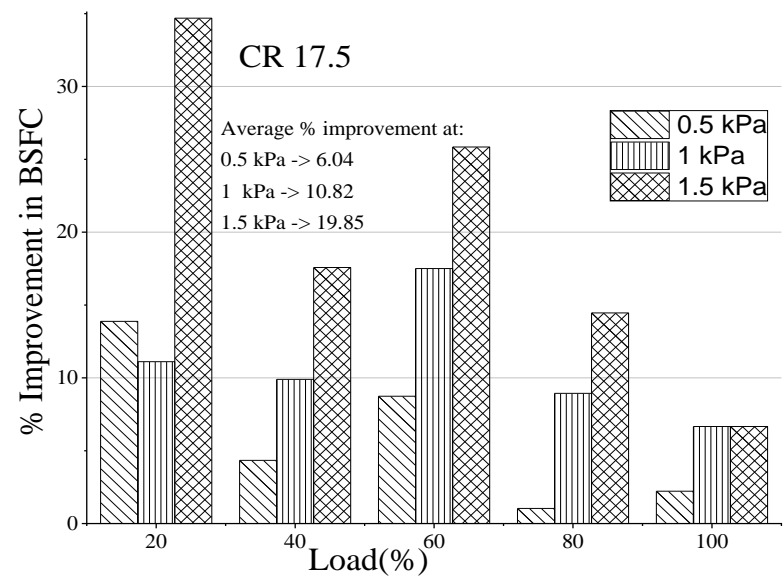

Figure 5. Percentage improvement in BSFC of BPs over NA

The percentage improvements for loads due to particular boosting pressure is averaged at appropriate $\mathrm{CR}$ and presented for all CRs in Figure 6. The upgrades in BSFC are calculated for boost pressures over NA at rated CR. It is noted that improvements are rising with the boosting pressure and CRs up to 17.5 and then decreased. The improvements in BSFC up to 17.5 due to an influence of boosting pressure was dominant as compared to CR, whereas at higher CR 18 may be the higher and more influencing friction loss which further added by boosting and hence relatively less improvement is observed. The maximum average BSFC improvement was $21.75 \%$ at $1.5 \mathrm{kPa}(\mathrm{g})$ at $\mathrm{CR} 17.5$.

\subsection{Brake thermal efficiency}

The brake thermal efficiency (BTE) at CR 17.5 is shown in Figure 7. The BTE increases with load and boost pressures. The improvements in BTE are higher at low and medium loads, and it is more at $\mathrm{BP} 1.5 \mathrm{kPa}$, and it is verified with an observation of BSFC improvements. Due to increase in boosting pressure, the inlet charge pressure, cylinder pressure increases owing to compression of residual gases present in the clearance volume. This positive effect of parameters facilitates the additional filling of air and increase in density and volumetric efficiency results in further increase in power and BTE.
The percentage improvements of BTE at BPs over NA at all loads are presented in Figure 8. The improvement in BTE decreases with increase in load and increases with BPs. With an increase in load, in-cylinder pressure and temperature gradually become influential and decreases the effect of BP. The BP increment causes the reduction in friction loss due to positive gas exchange process and significant reduction of pumping losses.

The maximum percentage improvement in BTE was $44.8 \%$ at $20 \%$ load and average percentage improvement observed for all loads at $0.5,1,1.5 \mathrm{kPa}(\mathrm{g})$ were $4.67 \%, 12.33 \%$, and $25.34 \%$ respectively.

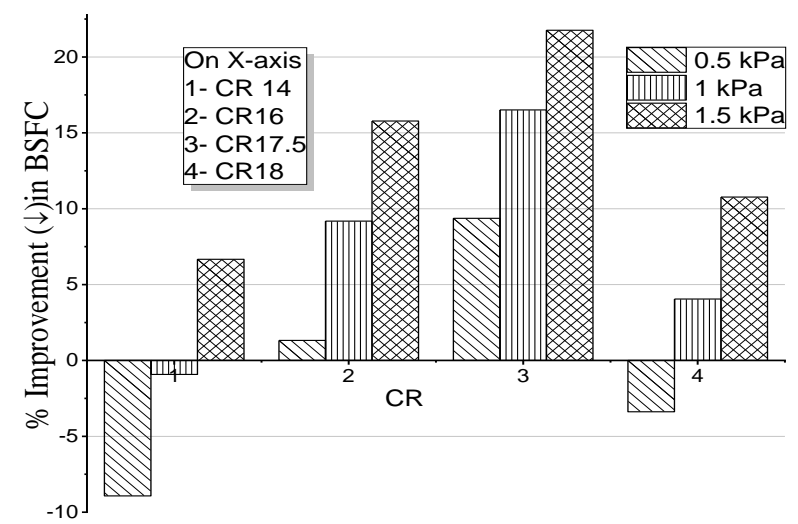

Figure 6. Variation of average improvement in BSFC with $\mathrm{CR}$ and $\mathrm{BP}$

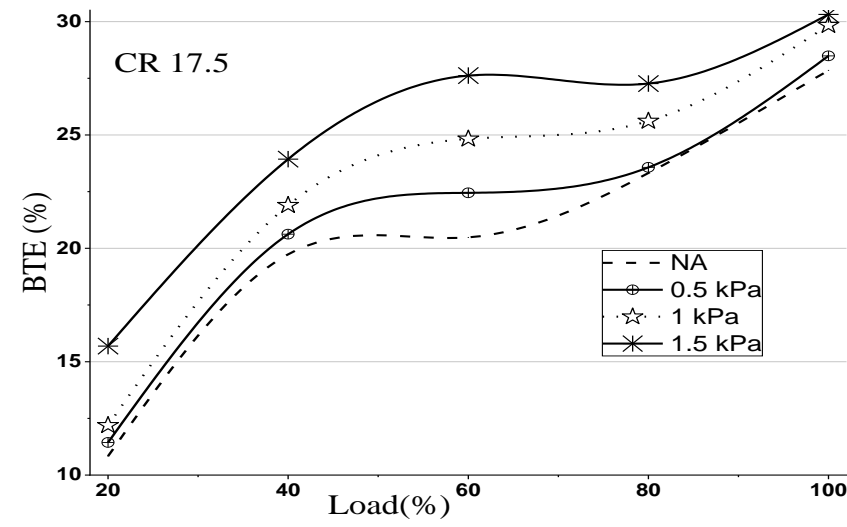

Figure 7. Variation of BTE with load and BP at CR 17.5

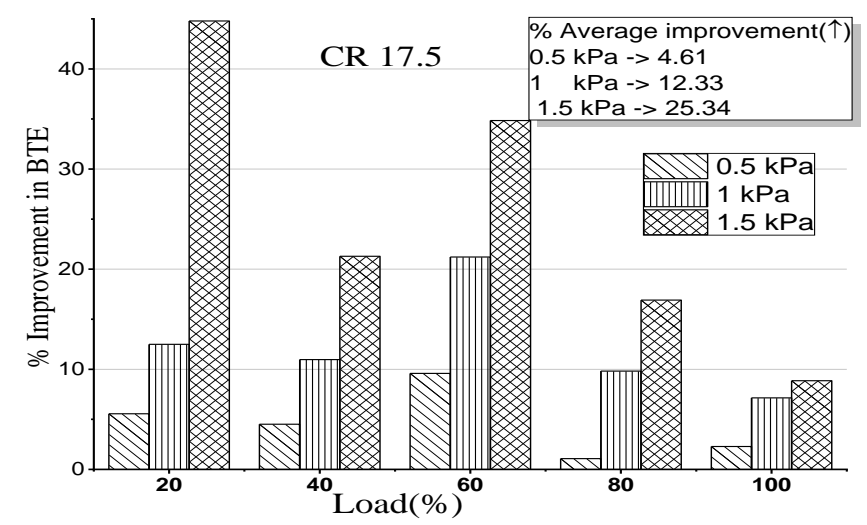

Figure 8. Percentage improvement in BTE 


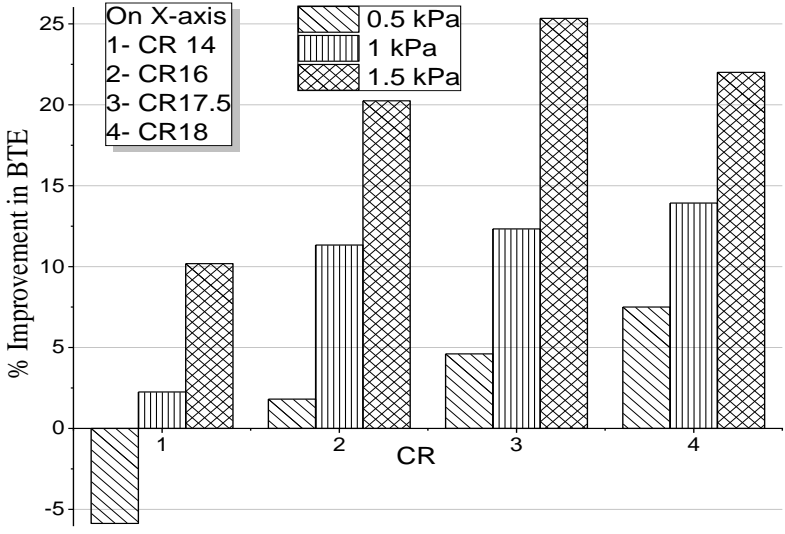

Figure 9. Variation of average improvement in BTE with CR and BPs

The improvements in BTE are averaged for all loads at particular BP and CR and depicted in Figure 9 for BPs and CRs. This figure shows the combined effect of BP and CR on BTE. At CR 14, due to lower CR, the in-cylinder pressure and temperature were not sufficient to burn the fuel entirely at NA, and $0.5 \mathrm{kPa}$ and has adverse effects, and it is improved at further increase in BP 1, 1.5 kPa. At CR 16, relatively higher pressure and temperature further supplemented by the BPs and observed improvement in BTE was more. This further rise in CR 17.5 due to the favorable condition of rated CR and BPs and noted improvement was maximum $25 \%$ at $1.5 \mathrm{kPa}$. The little bit reduction is observed at higher CR 18, due to higher friction losses in piston bearings.

\subsection{Exhaust gas temperature}

The exhaust gas temperature (EGT) indicates how efficiently fuel's energy has been utilized to convert into mechanical energy inside the cylinder. Higher exhaust gas temperature meant wastage of energy by late combustion of fuel during the expansion stroke and exhausted without being utilized. The Figure 10 depicts the EGT at rated CR 17.5. It is found that effect of BP (BP) increases the EGT at 20\% load only and at all subsequent loads it has decreased with increase in BPs. The increase of EGT at $20 \%$ load could be because of improvement in later stage of combustion (diffusion) and at the middle of the expansion stroke. Hence, even though improvement in combustion efficiency due to boosting pressure it is not utilized effectively and lost as exhaust gas temperature. However, in the later stage of loading conditions, it is decreased with increase in boosting pressure. This could be because of advancement of combustion towards TDC and effectively utilized the energy.

The Figure 11 illustrated the percentage change of EGT due to BPs as compared to NA at each load. At $20 \%$ load maximum increase in exhaust gas temperature was $2.3 \%$ at 1.5 $\mathrm{kPa}(\mathrm{g})$. Further increase in load, the EGT reduces with the BP due to increase in air turbulence and fuel efficiency. The maximum percentage reduction in EGT was $5 \%$ at $100 \%$ load $1.5 \mathrm{kPa}(\mathrm{g}) \mathrm{BP}$.

The total percentage improvement/ deterioration in EGT for $0.5 \mathrm{kPa}(\mathrm{g}) \mathrm{BP}$ is the average of all improvements at all loads. Similarly, calculated for other 2 BPs and portrayed in Figure 12. From the figure, it is noted that EGT is higher at lower CR as compared to rated CR. This could be because of incomplete combustion and longer ignition delay of fuel at lower CR. However it decreases with the increase in BP, it means improvement in the energy utilization of fuel. With further increase in CR 17.5 and 18, the EGT is less than rated EGT at all BPs.

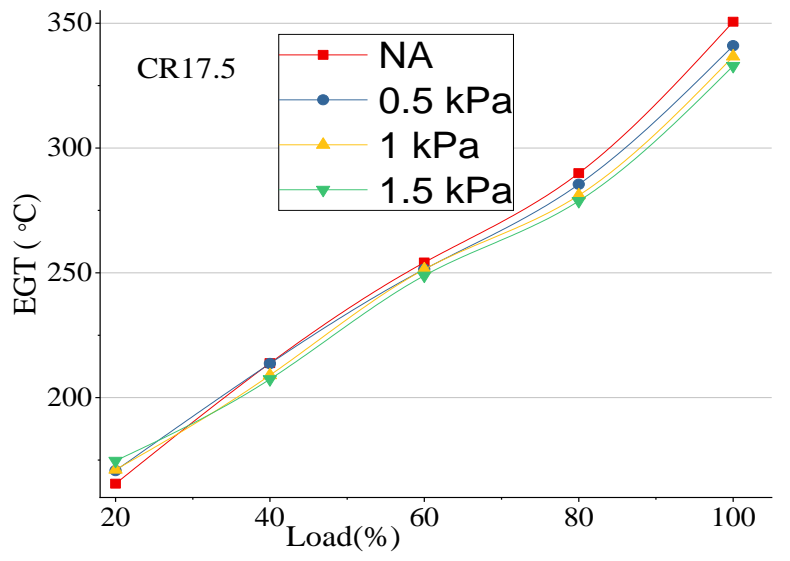

Figure 10. Exhaust gas temperature

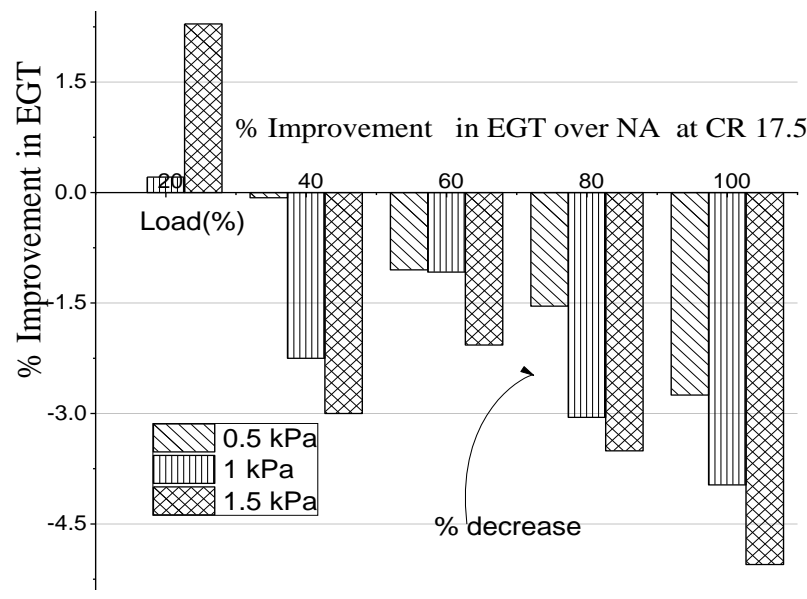

Figure 11. Percentage improvement

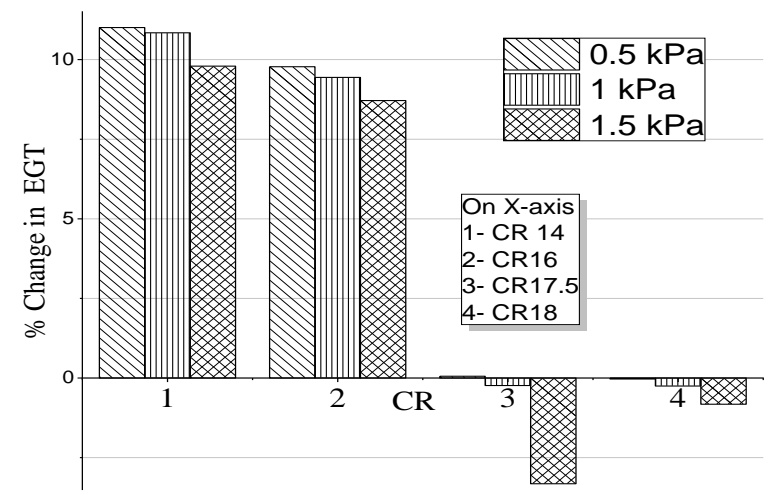

Figure 12. Variation of average improvement in EGT with $\mathrm{CR}$ and $\mathrm{BP}$

\section{ECONOMY OF ENGINE DOWNSIZING}

The economy of employing the supercharger for boosting purpose is calculated using the above-said equations 2,3 , and 4. As compared to NA at rated CR, the percentage increase in specific power for all BPs at all loads are averaged and presented in Figure 13 for all CRs. The specific power reports how effectively, the piston area is exploited for developing the 
power irrespective of the size of cylinder. From the figure, it is noted that specific power of engine increases with BPs at all CRs and with the rise in CR; it grows up to 17.5 and slightly decreases.

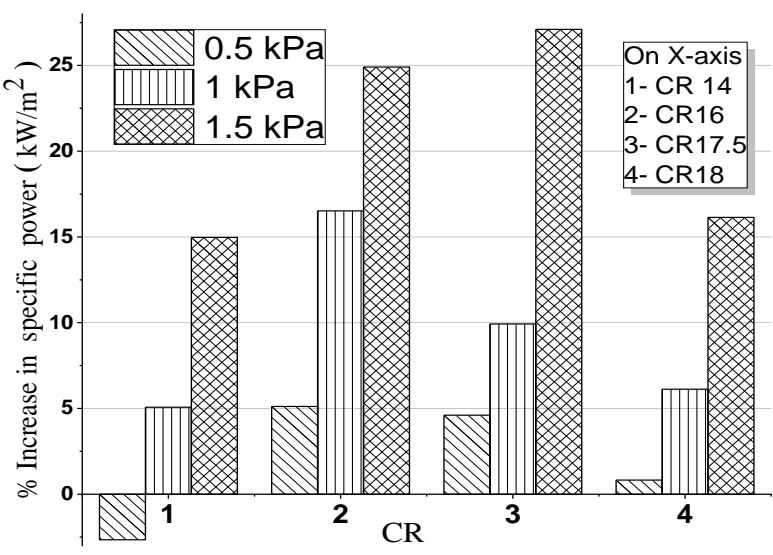

Figure 13. Variation of average percentage increase in specific power

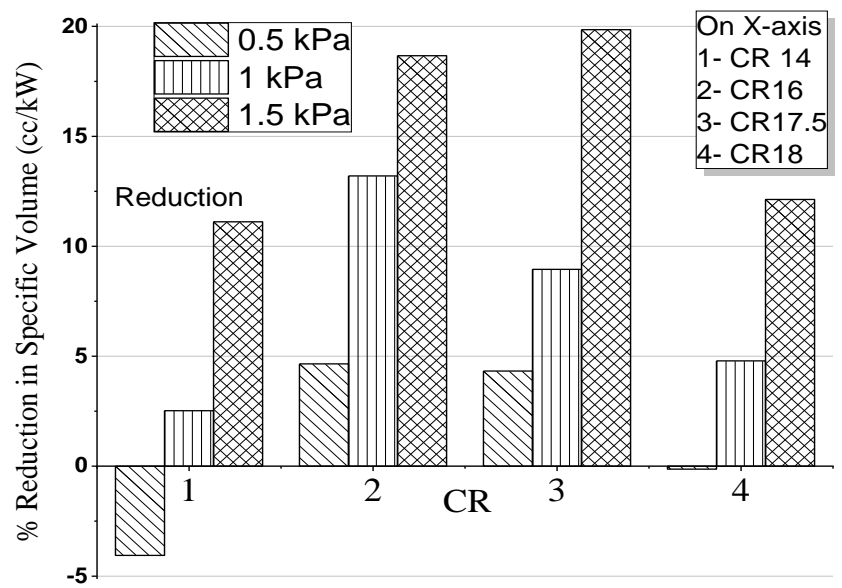

Figure 14. Variation of average percentage reduction in specific volume

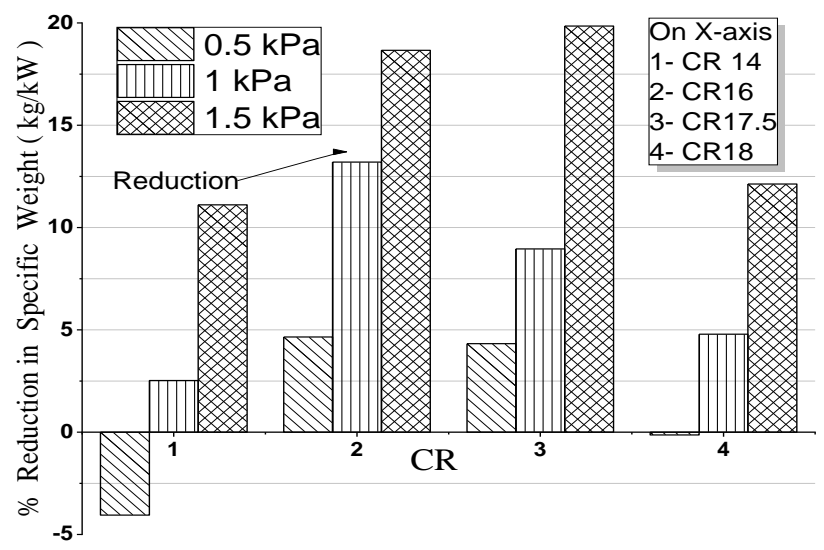

Figure 15. Variation of average percentage reduction in specific weight

The BP improves the indicated power at all CR and at the same time it decreases the friction power by reducing the pumping loss owing to improvement in specific power of the engine. The maximum percentage increase in specific power at CR 14, 16, 17.5, and 18 were observed as 15, 25, 27, and 16 respectively.

Similarly, the percentage reduction in the specific volume of the engine is calculated and illustrated in the Figure 14. The synergetic influences of $\mathrm{BP}$ and $\mathrm{CR}$ have revealed that engine volume has reduced significantly. This further could be helpful to design the small engine for improved power output with less weight and space. The economy of engine materials are utilized due to the combined effect of BP and CR are demonstrated in Figure 15 . The maximum percentage reduction in specific weight of the engine is $20 \%$ at $1.5 \mathrm{kPa}$ at CR 17.5 followed by $18.7 \%$ at CR 16 and $11 \%$ at CR14.

\section{CONCLUSIONS}

The exhaustive experimental study performed for investigating the combined influence of supercharging and $\mathrm{CR}$ on performance characteristics of DICI engine. Obtained results are compared with the standard operating condition at natural aspiration of the engine, and following concluding, comments are made.

(1) Power consumption by the supercharger is proportional to the boost pressure, and it is not affected by the compression ratio. The percentage of power consumption is less than benefits accrued due to the boosting at all CR.

(2) Benefits in the reduction of brake specific fuel consumption are more at partial load and less a full load at boost pressures and CRs.

(3) Brake thermal efficiency improvement was higher at low load and higher boost pressure and CR.

(4) Exhaust gas temperature reduced significantly at all loads and CR due to boosting.

Significant improvement is observed in specific weight, specific power and specific volume of the engine.

\section{ACKNOWLEDGMENT}

The authors are thankful to All India Council of Technical Education, Government of India, for their support towards carrying out research work under Quality Improvement Program.

\section{REFERENCES}

[1] Nelson SA, Filipi ZS, Assanis DN. (2003). The use of neural nets for matching fixed or variable geometry compressors with diesel engines. J Eng Gas Turbines Power 125: 572-579. https://doi.org/10.1115/1.1563239

[2] Cooper B, Jackson N, Beasley M. (2004). Technology development to meet the future demand for passenger car diesel engines with lower emissions and higher performance. In: SIA International Congress, The Diesel Engine: Today and Tomorrow, Ecole Centrale de Lyon, France, pp. 12-13.

[3] Alarcón R, Malagón-Romero D, Ladino A. (2017). Biodiesel production from waste frying oil and palm oil mixtures. Chemical Engineering Transactions 57: 571576. https://doi.org/10.3303/CET1757096

[4] Sulaiman S, Shah B, Jamal P. (2017). Production of biodiesel from palm oil using chemically treated fish 
bone catalyst. Chemical Engineering Transactions 56: 1525-1530. https://doi.org/10.3303/CET1756255

[5] Zhang L, Takatsuki T, Yokota K. (1994). An observation and analysis of the combustion under supercharging on a DI diesel engine. In: International Congress \& Exposition. SAE Technical Paper, pp. 11. https://doi.org/10.4271/940844

[6] Suzuki H. (1994). Effect of EGR on combustion and exhaust emission of a supercharged diesel engine. In: Proc. Spring Convention, p. 9432967. https://doi.org/10.4271/2009-01-1832

[7] Kobori S, Yokosuka A. (2003). Study on ignition delay in high turbo charged diesel engines. Nippon Kikai Gakkai Ronbunshu B Hen(Transactions Japan Soc Mech Eng Part B)(Japan) 15: 1966-1971. https://doi.org/10.1299/kikaib.69.1966

[8] Ishikawa N. (2012). A study on emissions improvement of a diesel engine equipped with a mechanical supercharger. Int J Engine Res 13: 99-107. https://doi.org/10.1177/1468087411434885

[9] The age of engine downsizing is over, says Volkswagen. In: Telegr. http://www.telegraph.co.uk/cars/news/ageengine-downsizing-says-volkswagen/. Accessed 19 Jan 2018.

[10] Is engine downsizing finally falling out of fashion?|Evo. In: evo,THE THRILL Driv. http://www.evo.co.uk/features/18753/is-enginedownsizing-finally-falling-out-of-fashion. Accessed 19 Jan 2018.

[11] Sroka ZJ. (2012). Some aspects of thermal load and operating indexes after downsizing for internal combustion engine. J Therm Anal Calorim 110:51-58. https://doi.org/10.1007/s10973-011-2064-x.

[12] Yoshimoto Y. (2016). Influence of supercharging on biodiesel combustion in a small single cylinder DI diesel engine. SAE Int.

[13] Amba Prasad Rao G, Mohan PR (2003). Effect of supercharging on the performance of a DI Diesel engine with cotton seed oil. Energy Convers Manag 44: 937944. https://doi.org/10.1016/S0196-8904(02)00095-X

[14] Jagadish D, Ravi Kumar P, Murthy KM. (2011). The effect of supercharging on performance and emission characteristics of compresion ignition engine with dieselethanol-ester blends. Therm Sci 15:1165-1174. https://doi.org/10.2298/TSCI100513042J.

[15] Joshi D, Viswanath PV, Sandeep B. (2014). The Effects of Supercharging on the Performance of C. I Engine Using Blends of Pre-Heated Cotton Seed Oil and Diesel as Alternate Fuel. In: Advance Research and Innovations in Mechanical, Material Science, Industrial Engineering and Management - ICARMMIEM: 110-113. https://doi.org/10.1016/s0140-6701(03)83102-8

[16] Mahmood Mousavi S, Abolfazli Esfahani J, Yazdi Mamaghani M. (2013). Alternative Equations to Compute the Network and the Thermal Efficiency of the Irreversible Diesel Cycle Using Genetic Algorithm. Am J Mech Eng 1: 119-125. https://doi.org/10.12691/ajme$1-5-3$

[17] Roberts M. (2002). Benefits and challenges of variable compression ratio ( VCR ). SAE Tech Pap 14: 03P-227. https://doi.org/10.4271/2003-01-0398

\section{NOMENCLATURE}

DICI direct injection compression ignition

BP boost pressure

$\mathrm{kPa}(\mathrm{g}) \quad$ kilo pascal (gauge)

$\mathrm{CR} \quad$ Compression ratio

BSFC brake specific fuel consumption

BTE brake thermal efficiency

EGT exhaust gas temperature

NA natural aspiration 